\title{
Mimarlık ve Tasarım Fakültesi Peyzaj Mimarlığı Bölüm Öğrencilerinin Mesleklerine Bakışlarının Belirlenmesi Üzerine Bir Araştırma
}

\author{
Neslihan DEMİRCAN ${ }^{1}$, Başak AYTATLI ${ }^{2}$, Nalân DEMİRCİOĞLU YILDIZ ${ }^{2 *}$ \\ ${ }^{1}$ Atatürk Üniversitesi, Mimarlık ve Tasarım Fakültesi, Mimarlık Bölümü, ERZURUM \\ ${ }^{2}$ Atatürk Üniversitesi, Mimarlık ve Tasarım Fakültesi, Peyzaj Mimarlığı Bölümü, ERZURUM
}

\section{Öz}

Nüfus artışı ve buna bağlı olarak gelişen kentleşme sonucu artan rekreasyonel ihtiyaç, ekosistem ve ekolojik dengenin sağlanmasında önemli bir meslek dalı olan Peyzaj Mimarlığı disiplininin önemini her geçen gün artırmaktadır. Peyzaj mimarlığı mesleği sürdürülebilir ekolojik düzenin yeniden sağlanmasına ve insan doğa ilişkisinin yeniden kurulmasına yönelik çalışmaları sürdürmektedir. Meslek seçimi insanın hayatı boyunca en önemli dönüm noktalarından biridir.

Eğitim alanında yapılacak planlama çalışmalarında etkinliğin sağlanabilmesi için katılımcı yaklaşımların geliştirilmesi önemlidir. Çalışmada Atatürk üniversitesi Mimarlık ve Tasarım Fakültesi, Peyzaj Mimarlığı Bölümünde okuyan öğrencilerin mesleklerini tercih etme tutumlarını belirlemeye yönelik bir anket çalışması gerçekleştirilmiştir.

Genel olarak öğrencilerin \%64'u peyzaj mimarlığı mesleğini bilerek ve isteyerek tercih etmişlerdir. \%45 oranında öğrenci ise gelecekte rahat bir şekilde iş imkânına kavuşacağını düşünmektedir. Genel olarak bütün veriler değerlendirildiğinde, öğrencilerin peyzaj mimarlığı bölümünde eğitim almaktan ve ileride mesleklerini yapacak olmaktan mutlu oldukları sonucuna ulaşılmıştır.

Anahtar Kelimeler: Peyzaj mimarlı̆̆ı, anket, rekreasyonel davranış.

\section{A Research on Determining The Perspectives of Faculty of Architecture and Design of Landscape Architecture Students To Their Professions}

\begin{abstract}
Population growth and resulting the urbanization increased recreational needs, increases the importance of the discipline of Landscape Architecture, which is an important profession in the provision of ecosystem and ecological balance.The profession of landscape architecture continues to ensure the sustainable ecological order and to establish the connections of people with nature. Choosing a career is one of the most important milestones in human life.

It is important to develop participatory approaches in order to ensure efficiency in planning studies in the field of education.In this study, a survey was conducted in order to determine the attitudes of the students who study in department of Landscape Architecture in Atatürk University Faculty of Architecture and Design.

In general, $64 \%$ of the students knowingly and willingly preferred the landscape architecture profession. $45 \%$ of the students think that they will have the opportunity to work comfortably in the future. When all the data are evaluated in general, it is concluded that the students are happy to study in the landscape architecture department and to be able to do their jobs in the future.
\end{abstract}

Keywords: Landscape architecture, survey, recreational behavior. 


\section{Giriş}

Küreselleşen dünyada yapılı çevrenin sürdürülebilirliğinin sağlanması ancak farklı meslek disiplinlerinin bu kaygıyı taşımasına bağlıdır. Bu amacı gerçekleştirecek en önemli meslek dalı mimarlık bilimidir. Le Corbusier (1928)'de de belirttiği gibi, mimarlık mesleği, diğer meslek disiplinlerine göre yok olmayıp, tersine farklı kollarla birlikte genişlemiştir (Gül ve ark.2011).

ABD' de 2010 yılında yapılan bir çalışmada, 5 kategoride (bilim ve teknoloji, sağlık hizmetleri, eğitim, iş ve finans ile yaratıcılık ve hizmet sektörü) bulunan meslek dallarının iyi ücret ve olanaklar ile her zaman çalışmalarını sürdürdükleri belirtilmiştir. Peyzaj Mimarlığı mesleği ise yaratıcılık ve hizmet sektörü içinde bulunmaktadır (Kaya, 2010). Bu bağlamda bir peyzaj mimarı, doğal ve yapay çevrenin ekolojik, ekonomik, fonksiyonel ve estetik ilkeler doğrultusunda, planlanması, tasarımı, koruma-kullanma dengesinin sağlanması ve çevrenin yönetilmesi gibi birçok sorumluluk üstlenmektedir. Bu şekilde yaşam mekânlarının iyileştirilmesi ve daha sağlıklı kentler oluşturulması sağlanmaktadır.

"Peyzaj”ın kelime anlamı "manzara" demektir ve dilimize Fransızca "Paysage" sözcügünden girmiştir. Kader ve Kupik (2011), peyzaj terimini bir coğrafi terim olarak ilk Alexander Von Humboldt'un yeryüzü parçasının karakteri olarak tanımladığını belirtmişlerdir. Manzara, doğa gibi görsel ortamların sergilendiği resimler içinde kullanılan peyzaj terimi sanatsal bir terim olarak da kullanılmaktadır (Aran 1965, Anonim 2009a). Gazvoda, (2002)'a göre peyzaj mimarlığı mesleği, karmaşık ve multidisipliner bir yapıya sahiptir. Rodiek ve Steiner (1998)'e göre ise peyzaj mimarlığı, planlama ve tasarım çalışmalarıyla, peyzajı biçimlendiren, mekan oluşturan ve insan aktivitelerini düzenleyen bir meslektir.

Amerikalı Frederick Law Olmsted 1857 yılında ilk kez “peyzaj mimarı” unvanını Central Park'ın projesinde kullanmıştır. ASLA (Amerikan Peyzaj Mimarları Birliği) 1899 yılında kurulmuş, Peyzaj Mimarlığı dersi ise ilk defa Harvard Üniversitesi’nde 1900 yilında müfredata koyulmuştur (ASLA 1999; Anonim 2009b).

Peyzaj Mimarlığı eğitimi ise ilk Ankara Yüksek Ziraat Enstitüsü’nde 1942-1948 yılında Bahçe Sanatı ismi ile başlamıştır. 1948-1950 yıllarında "Bahçe Mimarisi ve Süs Nebatları", 1952 yılında "Bahçe Mimarisi ve Ağaçlandırma Kürsüsü" olarak eğitimine devam etmiştir (Uzun ve Kesim, 2009). Peyzaj Mimarlığı ismini ise 1977 yılında almıştır (Gül ve ark., 2011). Günümüzde Peyzaj Mimarlığı Programı, 27 farklı üniversitede aktif olarak eğitim öğretim vermektedir.

Döşlü (2000)'e göre, geçmişi eskiye dayanan Peyzaj Mimarlığı mesleği, diğer planlama ve tasarım meslek disiplinlerine göre yasal ve yönetsel ölçekte geri planda kalmaktadır. Laurie (1997), Peyzaj Mimarlarının alternatif yaklaşımlarının, mesleğin konumunu ve geleceğini etkileyeceğini savunmuştur. Rodiek (2000)'e göre ise, peyzaj mimarlığı meslek stratejilerinin belirlenmesi ve yeni çalışma olanaklarının değerlendirilmesi ile mesleki etkinliğin artırılmasının sağlanabileceği, bunun da meslekte yeni heyecan ve güdülemeyi sağlayacağını belirtmiştir. Kaplan (2000)'a göre, Peyzaj Mimarlı̆̆ı mesleğinin, uzmanlık alanlarının yeniden belirlenmesi gerekmektedir. Özellikle Lovejoy (1993)'un çalışmasına yapmış olduğu atıfta peyzaj mimarların, ülkelerin çevre politikalarına aktif olarak katkı sağlayarak, büyük ölçekte planlama çalışmalarında görev almaları gerektiğini vurgulamıştır. Bunun için de, mesleği bekleyen olanak ve sorunların belirlenip, bunlara yönelik vizyon ve plan geliştirilmesi gerekmektedir (Everett, 1999).

Modern çağın imkânlarının ve teknolojinin artmasıyla oluşan, toplumda ve fiziksel çevrede görülen değişimlere paralel olarak peyzaj mimarlığı mesleğinin içerik ve alanları da genişlemiş ve değişmiştir. Kent halkı, doğal mekânları, modern mimari ve tasarımlarla bir arada görmeyi talep etmektedir (Kuban, 1998; Gül ve Akten, 2009).

Bireyin genel olarak hayatındaki mutluluğunu, optimum ekonomik ve sosyo-kültürel şartlar sağlandığı takdirde, sevdiği ve istediği mesleği yapabilmesi etkilemektedir. Mesleğini verimli ve doğru yapabilmesi daha öğrencilik yıllarında edindiği meslek bilinci ile kendini geliştirmesine bağlıdır (Yıldız ve ark., 2011). Gelişmiş ülkelerdeki eğitim sistemi öğrencilere sorgulama, eleştiri yapma, yeteneklerini keşfetme, merakını gidermek için araştırma yapma imkânı verirken; ülkemizde öğrencinin istek ve yetenekleri dışında ezbere ve hazır bilgi sunmaya dayalı bir sistem söz konusudur.

$\mathrm{Bu}$ durum eğitimin düzeyini ve kalitesini doğal olarak değiştirmektedir. Üniversite ve fakülte yapısı, yaşadıkları kentin konumu, imkânları ve eğitim kalitesi gibi birçok faktör, bilinçsiz tercihle gelen öğrencilerin bölümle olan ilişki ve diyaloglarının, bilinçli tercih yaparak gelen öğrencilere göre daha iyi olmasını sağlayabilir. 
Türkiye'de üniversite sınavlarına giren öğrencilerin büyük çoğunluğu, meslek seçimini rastgele ve bilinçsizce yapmaktadır. Dolayısıyla gelişigüzel okuduğu bir bölümden mezun olduklarında yeterince bilgi ve donanıma sahip olamamaktadırlar. Diğer yandan öğrencinin bu durumunda, ayrıca fiziksel koşulların yeterli olmaması, kentin ve üniversitenin adı, sosyal- kültürel imkânların azlığı da etkili olmaktadır. Ancak, öğrenci ilgi ve yetenekleri doğrultusunda meslek tercihi yaparsa, daha sonraki yaşamında başarılı, verimli ve mutlu olmaktadır (Sarıkaya ve Khorshid, 2009).

Bright (1999), Ayaşlıgil (2000), Topay ve Kaya (2007), Yücel ve ark.(2007), Atik ve ark.(2013), peyzaj mimarlığı mesleğini seçen öğrencilerin sosyal, kültürel ve ekonomik yapılarını belirleyerek, mesleklerine bakış açılarını belirlemeye çalışmışlardır.

Peyzaj Mimarlı̆̆ı mesleğini tercih eden öğrencilerin bilinçli, yetenekli ve donanımlı olmaları mesleğin gelişmesi ve tanınırlığını artıracaktır. Bu çalışma Erzurum kenti örneğinde, Peyzaj Mimarlığı Bölümünde okuyan öğrencilerin mesleklerine bakış açılarını ve bunu etkileyen faktörleri belirlemek amacıyla yapılmıştır.

\section{Materyal ve Metot}

Çalışma, Erzurum Atatürk Üniversitesi Ziraat Fakültesi’nde 1990 yllında kurulup, 2010 yılında Mimarlık ve Tasarım Fakültesi bünyesinde eğitimine devam eden Peyzaj Mimarlı̆̆ı Bölümünde, Peyzaj Mimarlığı bölüm öğrencilerinin, peyzaj mimarlı̆̆ı mesleğine, bakış açıları ortaya konmak için yapılmıştır.

Sayısal puan türü ile gelen öğrenciler arasından Mimarlık ve Tasarım Fakültesi Peyzaj Mimarlığı Bölümünden rastgele belirlenen toplam 100 öğrenciye anket çalışması uygulanmıştır. Sorular, bireysel özellikler ve meslek tercihlerini belirlemek için hazırlanmıştır. Peyzaj Mimarlığı mesleği hakkındaki düşünceleri değerlendirilmiştir. Anket soruları ile öğrencilerin mesleği tanıyıp tanımadıkları ve Peyzaj Mimarlığı tercih sırası, üniversitenin bulunduğu şehrin ne düzeyde etkili olduğu belirlenmeye çalışılmıştır.

Ankette yer alan derecelendirmeli soruların cevapları, SPSS Statistics 20 programında karşıslaştırmalı Ki-Kare ve Frekans analizleri ile değerlendirilmiştir. Bu sonuçlar Microsoft Excel programında değerlendirilerek grafik anlatımları hazırlanmış, değerlendirmeler ve yorumlamalar yapılmıştır.

\section{Bulgular}

Ankete katılan öğrencilerin yaklaşık \% 54'ü kadın,\% 46'sı ise erkek bireylerden oluşmaktadır. Katılımcılara ait bireysel özellikler Tablo 1'de verilmiştir.

Öğrencilerin üniversite sınavında şu an okudukları bölüme kaçıncı kez girişte yerleştiklerine dair sorulan soruda, ankete katılanların yaklaşık olarak yarısının (\%48) ikinci kez girişlerinde yerleştikleri belirlenmiştir (Tablo 2).

Peyzaj Mimarlığı Bölümü öğrencilerine sorulan "Bu meslek tercihiniz kaçıncı sıradaydı ?" sorusuna karşılık ise yaklaşık \% 50'si ilk beş tercihinin içinde yer aldığını belirtmiştir (Tablo 3).

Ankete katılan öğrencilere sınav sonucundaki beklentilerine dair sorulan soruda ise, bireylerin yaklaşık \% 67'sinin üniversitenin herhangi bir fakülte ve bölümüne rahatlıkla yerleşebilecek puan aldıklarını ifade etmişlerdir.

Öğrencilere tercih yaparken en çok önem verdikleri unsurun ne olduğu sorulmuş ve bireylerin yaklaşık \% 64'ü meslek, \%18’i üniversite adı ve \% 16’sı da diğer sebepler olarak cevap vermiş̧lerdir. Dolayısıyla öğrencilerin ileride yapmak istedikleri mesleğe öncelik verdiği görülmektedir.

Ankete katılan öğrencilere üniversite ve meslek seçiminde karar vermede etkili unsurların ne olduğu sorulduğunda, ise kendi fikirlerinin ağırlıkta olduğu (yaklaşı \% 67 oranında) daha sonra aile, rehber öğretmeni ve en son olarak tercih kılavuzu şeklinde sıraladıkları belirlenmiștir ve bireylerin yaklaşık \% $\% 5^{\prime}$ i tercih yapmadan önce bir ön araştırma yaptıklarını ve bilinçli bir şekilde geldiklerini ifade etmişlerdir. 
Tablo 1. Ankete katılan öğrencilerin bireysel özellikleri

\begin{tabular}{|c|c|c|c|}
\hline Bireysel özellikler & & Sayı & Yüzde (\%) \\
\hline \multirow{4}{*}{ Yaş } & 17 ve alt1 & 3 & 0,03 \\
\hline & $18-20$ & 34 & 0,34 \\
\hline & $21-25$ & 53 & 0,53 \\
\hline & 26 ve üzeri & 10 & 0,10 \\
\hline \multirow{2}{*}{ Cinsiyet } & Kadın & 54 & 0,53 \\
\hline & Erkek & 46 & 0,47 \\
\hline \multirow{2}{*}{ Medeni durum } & Evli & 2 & 0,02 \\
\hline & Bekar & 98 & 0,98 \\
\hline \multirow{3}{*}{ Doğum yeri } & Erzurum kent merkezi & 30 & 0,31 \\
\hline & İlçe ve köyü & 18 & 0,18 \\
\hline & Diğer iller & 52 & 0,51 \\
\hline \multirow{6}{*}{ Baba mesleği } & Esnaf & 11 & 0,11 \\
\hline & Memur & 20 & 0,19 \\
\hline & İşçi & 18 & 0,18 \\
\hline & Serbest & 22 & 0,23 \\
\hline & Çiftçi & 15 & 0,15 \\
\hline & Diğger & 14 & 0,14 \\
\hline
\end{tabular}

Tablo 2. Ankete katılan öğrencilerin kaçıncı girişte bölüme yerleştikleri

\begin{tabular}{lcc}
\hline & Sayı (n) & Yüzde (\%) \\
\hline İlk kez & 39 & 0,38 \\
İkinci kez & 48 & 0,49 \\
Üçüncü kez & 6 & 0,06 \\
Dördüncü kez & 3 & 0,03 \\
Diğer & 4 & 0,04 \\
Toplam & 100 & 100 \\
\hline
\end{tabular}

Tablo 3. Ankete katılan öğrencilerin bölümü tercih sıraları

\begin{tabular}{lcc}
\hline & Sayı (N) & Yüzde (\%) \\
\hline İlk beş & 51 & 0,51 \\
$\mathbf{5 - 1 0}$ & 22 & 0,22 \\
$\mathbf{1 0 - 1 5}$ & 13 & 0,13 \\
$\mathbf{1 5}$ ve sonrası & 14 & 0,14 \\
Toplam & 100 & 100 \\
\hline
\end{tabular}

Öğrencilere meslek seçerken ileriye dönük tercihlerini etkileyen unsurları önem sırasına göre puanlandırmaları istenmiş ve mezun olunca hemen işe başlamak (\%45), mesleği sevmek (\%24), toplum tarafindan saygı görmesi (\%16) ve kazancının yüksek olması (\%11) şeklinde sıralamışlardır.

Peyzaj Mimarlığı öğrencilerine mesleği daha önce duyup duymadıkları sorulmuş ve yaklaşık \%77'si evet cevabını vermişlerdir. Ayrıca yine mesleğin çalışma konularını da bilerek geldiklerini ifade eden yaklaşık \% 64 lük bir kısım mevcuttur. Ankete katılan öğrencilerin, peyzaj mimarlı̆ğ mesleğinin iş imkânlarına dair bilgilerinin olup olmadığı sorulmuş ve $\% 75$ oranında evet cevabı alınmıştır. 
Öğrencilere kentsel ve kırsal dış mekân planlama ve düzenlemelerini hangi meslek dalının yaptığı sorusu sorulduğunda \%77'si peyzaj mimarlığının, orman mühendisinin \%14, \% 6 lık kısım çevre mühendisinin yaptığını düşünmektedirler.

Peyzaj Mimarlığı öğrencilerine, tekrar tercih hakkı verildiği takdirde şu an okudukları bölümü başka nerede ve hangi üniversitede okumak istedikleri sorulmuştur. Öğrenciler, İstanbul Teknik Üni.- Mimarlık Fakültesi (\%22), Atatürk Üni.-Mimarlık ve Tasarım Fakültesi (\%18), Ankara Üni.-Ziraat Fakültesi şeklinde ilk üç üniversiteyi sıralamışlardır (Tablo 4)

Tablo 4. Ankete katılan öğrencileri gitmek istedikleri fakülteler

\begin{tabular}{lcc}
\hline Üniversite-Fakülte & Sayı & Yüzde \\
\hline İstanbul Teknik Üni.- Mimarlık Fakültesi & 22 & 0,22 \\
Atatürk Üni.-Mimarlık ve Tasarım Fakültesi & 18 & 0,18 \\
Ankara Üni.-Ziraat Fakültesi & 16 & 0,16 \\
Karadeniz teknik Üni.-Orman Fakültesi & 15 & 0,15 \\
Ege Üni-Ziraat Fakültesi & 10 & 0,1 \\
SDÜ-Mimarlık Fakültesi & 7 & 0,07 \\
Akdeniz Üni.-Mimarlık Fakültesi & 6 & 0,06 \\
Uludağ Üni.-Ziraat & 6 & 0,06 \\
Toplam & 100 & 0,99 \\
\hline
\end{tabular}

Ankete katılan öğrencilerin bireysel özellikleri ile üniversite ve meslek tercihleri arasında doğrudan bir ilişki olup olmadığına dair yapılan Ki-Kare istatistik analizinde bu özellikler önemli olarak bulunmuştur (Tablo 5).

Öğrencilerin meslek seçiminde ileriye dönük tercihlerini etkileyen unsurlar sorulduğunda yanıtlar, bireylerin cinsiyetlerine göre farklılık göstermiş̧tir. Bayan öğrenciler herhangi bir kaygı taşımadan mesleği sevdikleri için yapmayı istediklerini belirtirken; erkek öğrenciler kazancının yüksek olmasını ilk sırada önemli bulmuşlardır (Şekil 1).

Tablo 5. Ankete katılan kişilerin cinsiyet özellikleri ile mesleği tercihleri arasındaki ilişki

\begin{tabular}{llll}
\hline Chi-Square Tests & & & \\
\hline Pearson Chi-Square & Value & df & Asymptotic Significance (2-sided) \\
& $10.668^{\mathrm{a}}$ & 5 & .058 \\
Likelihood Ratio & 11.938 & 5 & .036 \\
\hline
\end{tabular}

Kikare'de güvenirlik katsayısı $\alpha \leq 0.005$ olan değerler anlamlı ve $0.005<\alpha<0.10$ olan değerler

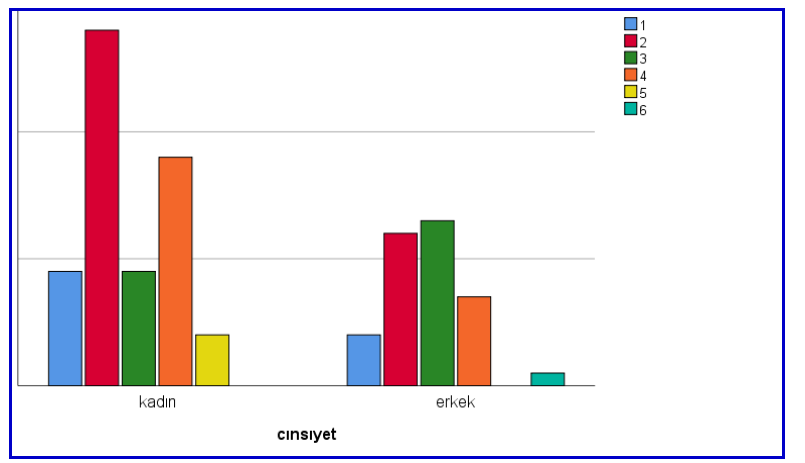

1.Mezun olunca işe başlamak

2.iş endişem yok, mesleği sevdiğim içim

3.Kazancin yüksek olması

4.Toplum tarafindan saygı görmesi

5.isminin cazip olması

6.Sadece okumuş olmak için

Şekil 1. Öğrencilerin cinsiyete bağlı olarak edindikleri meslekten beklentileri

Anket yaptığımız öğrenciler, farklı yaş gruplarından olduğu için sorulara verilen yanıtların bir kısmı da yaş 
faktörüne bağlı farklılık göstermiştir. Peyzaj mimarlığı bölümünün öğrencilerine meslekleri hakkında bilgilerinin olup olmadığını sorduğumuzda, 21-25 yaş aralığındaki ve genelde üniversiteye ikinci ve daha fazla kere tercihlerinde yerleşen öğrenciler meslek hakkında 18-20 yaş aralığındaki bireylerden daha fazla bilgisi olarak geldiklerini belirtmişlerdir (Tablo 6, Şekil 2).

Tablo 6. Ankete katılan kişilerin yaş özellikleri ile mesleği tercihleri arasındaki ilişki

\begin{tabular}{llll}
\hline Chi-Square Tests & & & \\
\hline Pearson Chi-Square & Value & df & Asymptotic Significance (2-sided) \\
& $20.289^{\mathrm{a}}$ & 6 & .002 \\
Likelihood Ratio & 21.225 & 6 & .002 \\
\hline
\end{tabular}

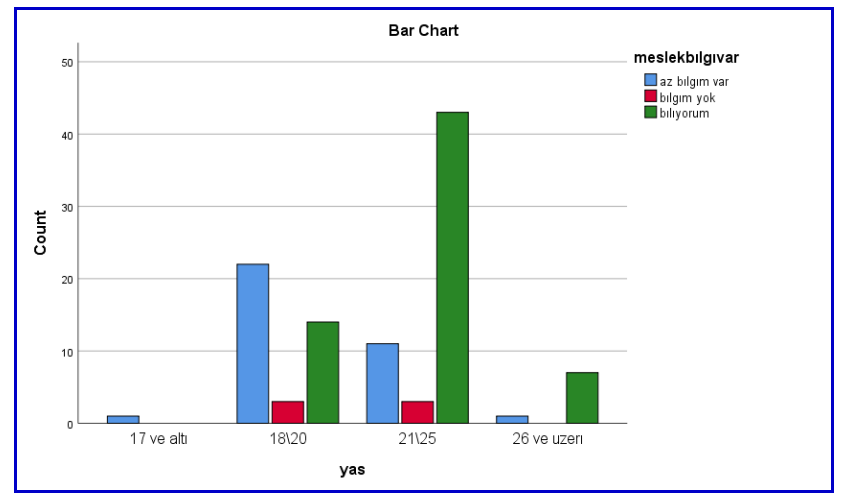

Şekil 2. Öğrencilerin yaş faktörüne bağlı meslek hakkında bilgisi

\section{Tartışma ve Sonuç}

Yapılan bu çalışmada, öğrencilerin meslek seçiminde ailelerin desteğiyle kendi fikirleri doğrultusunda tercih yapabildikleri gözlemlenmiştir. Sarıkaya ve Khorshid,( 2009) yaptıkları çalışmada, öğrencilerin genellikle okudukları bölümü isteyerek seçtiklerini ve özellikle tanıdık tavsiyesinden etkilendiklerini bulmuşlardır. Bu konuda yapılan diğer bir çalışmada da meslek seçiminde ailenin görüşlerinin tercihleri şekillendirdiği ifade edilmiştir (Owen vd., 2012). Clutter (2010) ailenin bireyin meslek seçimi üzerinde güçlü etkileri olduğunu belirtmiştir. Schoon ve Parsons (2002), çocuklarının meslek seçimlerinde ailelerin etkilerini şekillendiren en önemli nedenin ise sosyo-ekonomik yapı olduğunu belirlemişlerdir.

Öğrenciler, tercihlerini ekonomik ve diğer sosyal erişilebilirlik koşullarını da dikkate alarak, özellikle üniversite adı ve ileride yapmak istedikleri meslek önceliği ile yapmaktadırlar. Buna rağmen yaşadıkları kentte okumak isteyen öğrenciler de mevcuttur. Nitekim, Atik ve ark. (2013) tarafindan İnönü Üniversitesi'nde okuyan Peyzaj Mimarlığı Bölümü öğrencilerinin meslekten beklentilerini belirlemek için yapılan çalışma bölümü seçen öğrencilerin büyük çoğunluğu, meslek tercihlerinin doğru bir karar olduğunu, seçerken meslek hakkında bilgi sahibi olduklarını ve yine meslek içeriğinde tasarım ve çizim programlarının gerekliliğini belirtmişlerdir.

Özer ve ark. (2010) yapmış oldukları çalışmada, Erzurum Kenti’nde üniversite adaylarının Peyzaj Mimarlığı mesleğine bakış açılarının belirlenmesi üzerine yaptıkları çalışmada, öğrenciler henüz tercih aşamasındayken meslek hakkında yeterince bilgiye sahip olmadıklarını ve duymadıklarını belirtmişken; yapılan bu çalışmada 2010 yılı itibariyle Erzurum Atatürk Üniversitesi'nde Mimarlık ve Tasarım fakültesi bünyesinde son 8 yılda, öncesinde yaklaşık 28 yıllık bir geçmişe sahip peyzaj mimarlığı bölümüne öğrenciler gerek medyadan gerek arkadaşları ve çevredeki değişimlerden haberdar olmaları ve yönlendirilmeleriyle son derece bilinçli ve istekli tercih yaparak geldikleri tespit edilmiştir. Yine Özer ve ark. yapmış olduğu çalışmada, 2010 yılında öğrencilerin \%7 lik bir kısmı ilk beşte bu bölümü tercih ederken, yapılan çalışma sonucunda, bu oranın \% 51'e kadar yükseldiği belirlenmiştir. Dolayısıyla üniversiteyi, fakülteyi ve okudukları bölümü bilerek ve kendi istekleri doğrultusunda gelen öğrencilerin sayısı her geçen yıl artmaktadır.

\section{Kaynaklar}

1. Aran S (1965). Peyzaj Mimarisi I, Ders Notları, Ankara Üniversitesi Ziraat Fakültesi, Ankara. 
2. ASLA (1999). What is Landscape Architecture? http://www.asla.org /asla/nonmembers/What is Asla.html..

3. Anonim (2009a). Peyzaj Nedir? http://peyzaj.org. Erişim 2009.

4. Anonim (2009b). Ankara Üniversitesi Ziraat Fakültesi Peyzaj Mimarlığı. http://www.agri.ankara.edu.tr

5. Atik A., Yılmaz B., Aslan F., Ateş O., Taçoral E.,(2013). Peyzaj Mimarlığı Öğrencilerinin Eğitim ve Meslekten Beklentilerinin İnönü Üniversitesi Örneğinde İncelenmesi Üzerine Bir Araştırma, İnönü Üniversitesi Sanat Ve Tasarım Dergisi, İnönü University Journal of Art and Design ISSN: 1309-9876 EISSN: 1309-9884 Cilt/Vol. 3 Say1/No.8 (2013): 105-122

6. Ayaşlıgil T (2000). Yeni Bin Yıla Girerken Peyzaj Mimarlığı Eğitimi. TMMOB Peyzaj Mimarları Odası Peyzaj Mimarlı̆̆ Kongresi 2000 Bildiriler, Ankara, s. 555-564.

7. Bright AD (1999). The Effects of environmental coursework on student perception of environment. In: Proceedings of the 1998 Northeastern Recreation Research Symposium, Pennsylvania, USA,

8. Clutter C. (2010). The effects of parental influence on their children's career choices. Yüksek lisans tezi. Kansas State University, Manhattan.

9. Döşlü D (2000). Türkiye’de Peyzaj Mimarlığı'nın kamu ve özel sektörde sahip olduğu yasal haklar ve mesleğin hukuksal boyutu. TMMOB Peyzaj Mimarları Odası Peyzaj Mimarlığı Kongresi 2000 Bildiriler, Ankara, s. 19-28.

10. Everett LS (1999). Introduction. iii-iv (in ASLA/LAF Summit White Papers. American Society of Landscape Architects, www.asla.org.

11. Gazvoda D (2002). Characteristics of modern landscape architecture and its education. Landscape and Urban Planning, 60 (2002) 117-133.

12. Gül A, Akten M (2009). Peyzaj Mimarlığına Giriş Ders Notları.SDU Orman Fak. Peyzaj Mimarlığı Bölümü, Isparta.(Basılmamış).

13. Gül A, Örücü KÖ, Eraslan Ş (2011). Mezun peyzaj mimarlarının eğitim ve öğretimden beklentileri. SDÜ Orman Fakültesi Dergisi, (12), 31-140. http://dergipark.gov.tr/download/article-file/195786.

14. Özer S, Sezen I, Demircan N (2010). Erzurum Kentinde Üniversite Adaylarının Peyzaj Mimarlığı Mesleğine Bakışlarının Belirlenmesi Üzerine Bir Araştırma, Akdeniz Üniversitesi Ziraat Fakültesi Dergisi (2010) 23(1): 23-29, www.Ziraatdergi.Akdeniz.Edu.Tr (C) Akdeniz Üniversitesi Ziraat Fakültesi

15. Kaplan A (2000). Peyzaj Mimarlığı Meslek Disiplinine Eleştirel bir Bakış. Peyzaj Mimarlığı Kongresi, TMMOB, Peyzaj Mimarları Odası.191-214. Ankara.

16. Kader Ş, Kupik M (2011). Peyzaj mimarisinde tasarım ve proje uygulama, 169, http://www.kitapark.com/pdf/peyzajda-tasarim-ve-uygulama.pdf.

17. Kaya M (2010). Eskişehir Osmangazi Üniversitesi Teknoloji Araştırma Merkezi (TEKAM) Müdürü.https://www.ogu.edu.tr/images/birimduyuru/2009122395917.ppt

18. Kuban D (1998). Mimarlık Sözlüğü, Yem Yayını, İstanbul

19. Laurie M (1997). Landscape Architecture and the changing city. In: Thompson GF, Steiner FR (Ed's), Ecological Design and Planning. John Wiley and Sons, New York, pp. 155-166.

20. Owen KF, Kepir DD, Özdemir S, Ulaş Ö, Yılmaz O (2012). Üniversite öğrencilerinin bölüm seçme nedenleri. Mersin Üniver-sitesi Eğitim Fakültesi Dergisi, 8(3) 135-151. http://dergipark.ulakbim.gov.tr/mersinefd/article/view/1002000263/1002000217.

21. Rodiek JE, Steiner (1998). Special Issue: Landscape Architecture Research and Education.Landscape and Urban Planning (42): 73-74p.

22. Rodiek JE (2000). Viewpoint on the environment: the next millennium. Landscape and Urban Planning (47): 103-104.

23. Sarıkaya T, Khorshid L (2009). Üniversite öğrencilerinin meslek seçimini etkileyen etmenlerin incelenmesi: Üniversite öğrencilerinin meslek seçimi. Türk Eğitim Bilimleri Dergisi, 7, 393-423.

24. Schoon I, Parsons S (2002). Teenage aspirations for future careers and occupational outcomes. Journal of Vocational Behavior, 60, 262-288.

25. Topay M, Kaya LG (2007). Türkiye'de Peyzaj Mimarlığı Eğitimi Alan Öğrencilerin Profili. TMMOB Peyzaj Mimarları Odası Peyzaj Mimarlığı 3. Kongresi Bildiriler, ANTALYA, s. 554-557.

26. Uzun O, Kesim G (2009). Türkiyede ${ }^{e c}$ ki Peyzaj Planlama Eğitimi Üzerine Bazı Görüş ve Öneriler. Peyzaj Planlama ve Tasarım Sempozyumu. Ankara Üniversitesi Ziraat Fakültesi Peyzaj Mimarlığı Bölümü. Ankara

27. Yıldız ND, Demir M, Aytatı B, Göktuğ TH (2011). Peyzaj Mimarlığı Eğitiminde Kadın. İnönü Üniversitesi Sanat ve Tasarım Dergisi. Özel Sayı(2):1074-83.

28. Yücel M, Yılmaz KT, Say N, Alphan H (2007). Peyzaj Mimarlığı eğitiminde yeniden yapılanma. TMMOB Peyzaj Mimarları Odası Peyzaj Mimarlığı 3. Kongresi Bildiriler, Antalya, s. 425-431. 